\title{
Intraspecific variability and mechanisms of pea (Pisum sativum L.) tolerance to toxic metals
}

\author{
Belimov A.A. ${ }^{*}$, Vishnyakova M.A. ${ }^{2}$, Shaposhnikov A.I. ${ }^{1}$, Azarova T.S. ${ }^{1}$, \\ Makarova N.M. ${ }^{1}$, Sekste E.A. ${ }^{1}$, Semenova E.V. ${ }^{2}$, Kosareva I.A. ${ }^{2}$, Safronova V.I. ${ }^{1}$ \\ ${ }^{1}$ All-Russian Research Institute for Agricultural Microbiology, St. Petersburg, Russia \\ ${ }^{2}$ N.I. Vavilov All-Russian Institute of Plant Genetic Resources (VIR), St. Petersburg, Russia \\ *e-mail: belimov@rambler.ru
}

Heavy metals are among the most common pollutants of agricultural lands. Remediation of such massive areas is difficult or impossible. Selection of resistant varieties with reduced accumulation of heavy metals can be a promising approach for obtaining environmentally friendly crop production on polluted soils. The aim of the present work was to study the intraspecific variability of pea (Pisum sativum L.) for resistance to toxic metals (Cd and $\mathrm{Al})$ and for the ability to accumulate and transport various heavy metals $(\mathrm{Cd}, \mathrm{Co}, \mathrm{Cu}, \mathrm{Ni}, \mathrm{Pb}$ and $\mathrm{Zn})$ from the root to the shoot and seed. A series of vegetation experiments were carried out in which the plants were grown under hydroponic conditions or in a soil supplemented with elevated concentrations of various metals. The content of heavy metals and nutrients in plants was determined using an ICPE9000 spectrometer. The objects of research were more than 200 pea genotypes (primitive and modern cultivars, belonging to different subspecies and having various geographic origin) originated from the VIR collection (St. Petersburg). It was established that pea has a very large variability in resistance to cadmium and aluminum, as well as the content of heavy metals. Correlations were found between the content of various metals in the shoots and seeds of plants. It has been established that important mechanisms of pea resistance to $\mathrm{Cd}$ and $\mathrm{Al}$ are maintaining of nutrient homeostasis and modulating $\mathrm{pH}$ of the rhizosphere. An additional mechanism was related to formation of efficient symbiosis with microorganisms such as nodule bacteria, endomycorrhizal fungi and plant growth promoting rhizobacteria. The obtained results can be useful for successful selection and breeding programs aimed at creating plant cultivars with high productivity and quality products cultivating on contaminated and acid soils.

Acknowledgements: The work was supported by the Russian Science Foundation (14-16-00137, 16-16-00080, 19-16-00097, 17-14-01363). 